2017-09

\title{
In situ determination of trace elements in Fucus spp. by field-portable-XRF
}

\section{Turner, Andrew}

http://hdl.handle.net/10026.1/8819

10.1016/j.scitotenv.2017.03.091

Science of The Total Environment

Elsevier BV

All content in PEARL is protected by copyright law. Author manuscripts are made available in accordance with publisher policies. Please cite only the published version using the details provided on the item record or document. In the absence of an open licence (e.g. Creative Commons), permissions for further reuse of content should be sought from the publisher or author. 

field-portable-XRF

14 *Corresponding author. Tel: +44 1752 584570; Fax: +44 1752 584710; e-mail:

15 aturner@plymouth.ac.uk

18 Accepted 9 March 2017

19 http://dx.doi.org/10.1016/j.scitotenv.2017.03.091

20 Embargo period 1/9/2019

21

22

23 


\section{Abstract}

25 Fresh and freeze-dried sample sections of the coastal macroalgae, Fucus serratus and F.

26 vesiculosus, and the brackish water macroalga, F. ceranoides, have been analysed for trace

27 elements by field-portable-X-ray fluorescence (FP-XRF) spectrometry using a Niton XL3t in

28 a low density mode with thickness correction. When analysed fresh in a laboratory accessory

29 stand for a period of 200 seconds, $\mathrm{As}, \mathrm{Br}, \mathrm{Fe}$ and $\mathrm{Zn}$ were registered in the apex, mid-frond

30 and lower stipe of all species, with detection limits of a few $\mu \mathrm{g} \mathrm{g}^{-1}$ (As) or a few tens of $\mu \mathrm{g} \mathrm{g}^{-}$

$31{ }^{1}(\mathrm{Br}, \mathrm{Fe}, \mathrm{Zn})$; when analysed dry under the same conditions, concentrations returned were

32 systematically higher and $\mathrm{Cu}$ and $\mathrm{Pb}$ were detected in a number of $F$. ceranoides sections.

33 Concentrations arising from both approaches on a dry weight basis were highly correlated,

34 with deviations from unit slope attributed to the absorption of fluorescent $\mathrm{x}$-rays by internal

35 and surficial water when analysed fresh. With algorithms correcting for the effects of water

36 on mass and x-ray absorption, sections of $F$. vesiculosus and $F$. ceranoides were analysed in

37 situ with the XRF connected to a mobile stand and laptop. Dry weight concentrations

38 returned for As and $\mathrm{Zn}$ were significantly correlated with respective concentrations

39 subsequently determined by ICP-MS following acid digestion and with a slope close to

40 unity; lower concentrations of Fe returned by ICP were attributed to the incomplete acid

41 digestion of silt particles that evaded an initial cleaning step, while $\mathrm{Br}$ concentrations could

42 not be verified independently because of loss of volatile forms during digestion. The in situ

43 determination of trace elements in fucoids by FP-XRF provides a rapid and non-destructive

44 means of monitoring environmental quality and identifying hot-spots of contamination, and

45 enables a research strategy to be developed iteratively that is informed by immediate results.

47 Keywords: macroalgae; fucoids; FP-XRF; monitoring; trace elements; ICP-MS 
49 Marine macroalgae represent a large and diverse group of primary-producing organisms in

50 the coastal zone that create habitat structure, provide food, promote biodiversity and serve as

51 a carbon sink (Duarte et al., 2013; Matias et al., 2015). Macroalgae also have an economic

52 value, acting as a source of food, nutrients and medicines for human consumption and

53 offering a means of bioremediation and a potential bioenergy resource (Bruhn et al., 2011;

54 Tabarsa et al., 2012). Being sessile, macroalgae are influenced directly by ambient

55 environmental conditions, and in this respect the distribution and occurrence of certain

56 species may often reflect local water quality (Guinda et al., 2008). Moreover, because of

57 their thick cell walls and high polysaccharide content, macroalgae are also able to

58 accumulate many aqueous contaminants, and in particular trace metals and metalloids, to

59 concentrations several thousand times higher than the ambient water column (Zbikowski et

60 al., 2006). Consequently, many species act as vehicles for the transfer of contaminants up the

61 food chain (Chan et al., 2003; Mulholland and Turner, 2011) and serve as useful biomonitors

62 that provide a direct and integrated assessment of bioavailable contaminants over a period of

63 time (Cairrão et al., 2007; Boubonari et al., 2008). The littoral brown fucoids are particularly

64 useful in the latter respect because of their extensive distribution, ease of identification and

65 sampling, tolerance of wide variations of temperature and salinity, abundance all year round

66 and limited ability to regulate contaminant concentrations (Martin et al., 1997; Rainbow,

67 2006; Sondergaard et al., 2014). Accordingly, Fucus spp. have been selected for inclusion in

68 the Environmental Specimen Banks (ECBs) of several European countries in order to

69 monitor long-term changes in anthropogenic contamination (Viana et al., 2010; Rüdel et al.,

70 2010).

72 As commonly employed biomonitor organisms, there is a requirement for the routine

73 determination of trace elements in macroalgae. Conventionally, analysis is performed on 
74 dried samples that have been digested in hot, concentrated acid by, for example, atomic

75 absorption spectrometry (Reis et al., 2014) or inductively coupled plasma (ICP)

76 spectrometry (Brito et al., 2012). This approach can, however, be time-consuming, labour-

77 intensive and costly, and the destruction of samples has implications for the long-term

78 viability of archived specimen banks. Recently, we investigated the feasibility of field

79 portable-X-ray fluorescence (FP-XRF) spectrometry as a rapid, non-destructive means of

80 determining trace elements in various species of macroalgae (Bull et al., 2017). Specifically,

81 we employed a Niton XL3t spectrometer configured in a low density, 'plastics' mode and

82 with a corrective algorithm for sample thickness to measure dried samples housed in a

83 laboratory accessory stand. For the elements that were detected, there was a significant

84 correlation between concentrations measured directly and those returned independently by

85 ICP-mass spectrometry following $\mathrm{HNO}_{3}$ digestion, with relationships satisfying the EPA

86 definitive level criterion for As and quantitative screening level for $\mathrm{Cu}$ and $\mathrm{Zn}$

87 (Environmental Protection Agency, 2007).

89 In order to further the XRF approach for measurements of trace elements in macroalgae in

90 situ, the effects of water, as a contributor to both sample mass and x-ray absorption, need to

91 be accounted for and factored in to any calibration. To this end, the present study compares

92 trace element concentrations returned by FP-XRF for different species of macroalgae

93 analysed both in the fresh and freeze-dried states. Specifically, fucoids were selected because

94 of their importance in coastal biomonitoring and their relatively high thickness (for x-ray

95 absorption) compared with other species of macroalgae (Bull et al., 2017). With the effects

96 of water empirically quantified, the practicalities and challenges of deploying the XRF in the

97 field for the direct measurement of trace elements in macroalgae are discussed. 


\subsection{Sampling and sample preparation}

103 Whole samples of fucoid were handpicked at low tide in July 2016 from two sites within 25

104 minutes' driving distance of the laboratory at Plymouth University (Figure 1). At Firestone

105 Bay, a small, pebble-sand beach in the coastal embayment of Plymouth Sound, five specimens of two coastal fucoids, $F$. serratus and $F$. vesiculosus, were collected from the rocky substrates of the littoral zone and stored in a cool box in a series of zip-lock polyethylene bags. From the intertidal mudflats of the upper Tavy Estuary, a tidal tributary

109 of the Tamar Estuary and an environment impacted by historical mining activities, ten

110 specimens of $F$. ceranoides, a brackish water fucoid, were collected and stored likewise. In 111 the laboratory, samples of $F$. serratus and $F$. vesiculosus were divided and subjected to two 112 different methods of clearing sediment and epiphytes from the surface; thus, one half was

113 cleaned in Millipore Milli-Q water (MQW) with the aid of a Nylon brush and subsequently 114 scraped with a plastic spatula after applying a $10 \%$ solution of ethanol to the tissue surface, 115 while the other half was cleaned with MQW only. After blotting dry with 3-ply hygiene roll, 116 all plants were dissected on a plastic tray using a stainless steel blade, with $\sim 5 \mathrm{~cm}$ sections 117 of the apex, mid-frond and lower stipe (just above the holdfast) from each plant retained and stored in individual specimen bags. Because of the smaller size of $F$. ceranoides and results

119 arising from the cleaning methods of the two coastal macroalgae, samples of the brackish 120 water fucoid were cleaned in MQW only before being dissected likewise. 


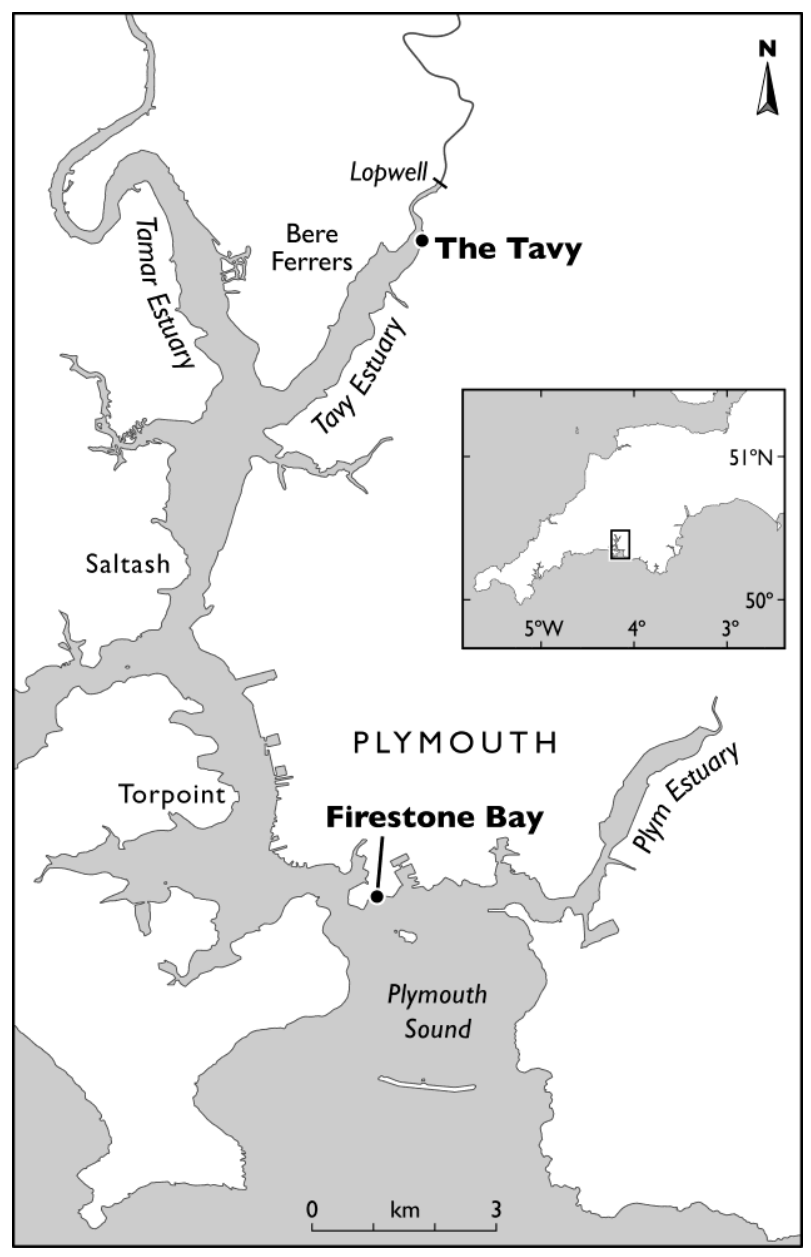

128 Figure 1: The sampling locations for the fucoid macroalgae.

\subsection{FP-XRF analysis}

131 Sample sections processed in the laboratory $(n=90)$ were analysed for trace elements (As,

$132 \mathrm{Br}, \mathrm{Cd}, \mathrm{Cr}, \mathrm{Cu}, \mathrm{Fe}, \mathrm{Hg}, \mathrm{Ni}, \mathrm{Pb}$ and $\mathrm{Zn}$ ) directly and without drying by energy dispersive FP-

133 XRF using a battery-powered, $1.3 \mathrm{~kg}$ Niton analyser (model XL3t 950 He GOLDD+) housed

134 in a ThermoScientific accessory stand of steel construction and tungsten-plastic shielding

135 (PN 420-017; weight $\sim 10 \mathrm{~kg}$, chamber volume $\left.=4000 \mathrm{~cm}^{3}\right)$. Analysis was performed in a

136 low density mode that uses a fundamental parameters-based alpha coefficient correction

137 model (Turner and Solman, 2016). Because the intensity of fluorescence generated by low

138 density and weakly absorbing samples is dependent on the thickness of material, a corrective

139 algorithm (down to $50 \mu \mathrm{m}$ ) was also applied after section thickness had been measured in

$140 \mathrm{~mm}$ and to two decimal places using digital callipers. With plastic tweezers, samples were 
142 carefully such that the smoothest and flattest part of the macroalgal section lay directly and

143 centrally above the $8 \mathrm{~mm}$ XRF detector window. After closing the accessory stand lid, the

144 XRF was activated remotely and via USB using a Fujitsu laptop computer. Analysis was

145 tested for a variety of conditions of which a collimation of $8 \mathrm{~mm}$ and a counting period of

146200 seconds, comprising 150 seconds at $50 \mathrm{kV}$ and $40 \mu \mathrm{A}$ and 50 seconds at $20 \mathrm{kV}$ and 100

$147 \mu \mathrm{A}$, appeared to be optimal in terms of detection, error and sample throughput. To check the 148 performance of the XRF and as an analytical quality control, Niton polyethylene reference

149 discs impregnated with known concentrations of various trace elements (PN 180-619,

150 LOT\#T-18 and PN 180-554, batch SN PE-071-N) were analysed throughout each

151 measurement session. On completion of measurements, spectra and elemental concentrations

152 (in $\mu \mathrm{g} \mathrm{g}^{-1}$ and with a counting error of $2 \sigma$ ) were downloaded to the laptop using Niton Data

153 Transfer PC software.

155 Immediately after sample measurement, individual macroalgal sections were weighed using

156 a five-figure Sartorius analytical balance before being returned to their original specimen

157 bags and freeze-dried for $48 \mathrm{~h}$ using an Edwards Super Modulyo. Dried sections were then

158 re-analysed by XRF under the operating conditions described above and after appropriate

159 (dry) thickness correction, before being re-weighed, returned to their specimen bags and

160 stored under desiccation pending acid digestion (see below).

\subsection{Macroalgae digestion and analysis by ICP-MS}

163 As an independent measure of trace elements in the macroalgae, all freeze-dried sample

164 sections were subsequently acid-digested and analysed by inductively coupled plasma-mass

165 spectrometry (ICP-MS). Thus, samples of about $0.1 \mathrm{~g}$ were accurately weighed into

166 individual Teflon tubes to which $2.5 \mathrm{ml}$ aliquots of $\mathrm{HNO}_{3}$ (Fisher Chemical TraceMetal ${ }^{\mathrm{TM}}$ 
Grade) were added. The contents were digested in a CEM MARS 5 XPRESS microwave at $1600 \mathrm{~W}$ for $45 \mathrm{~min}$ before being allowed to cool to room temperature. Digests were then

169 washed into individual $10 \mathrm{ml}$ volumetric flasks and diluted to mark with ultra-pure Millipore

170 Milli-Q water. For an assessment of digestion efficacy and analytical accuracy, a fucoid

171 reference material (Fucus vesiculosus, ERM-CD200; certified for $\mathrm{As}, \mathrm{Br}, \mathrm{Cd}, \mathrm{Cu}, \mathrm{Fe}, \mathrm{Hg}$, $172 \mathrm{~Pb}, \mathrm{Se}$ and $\mathrm{Zn}$ ) was digested in triplicate likewise.

174 Digests were analysed for elements that had been detected by XRF using a collision cell-

175 ICP-MS (Thermo X-series II, Thermoelemental, Winsford, UK) with a concentric glass 176 nebuliser and conical spray chamber. RF power was set at $1400 \mathrm{~W}$ and coolant, auxiliary, nebuliser and collision cell gas flows rates were $13 \mathrm{~L} \mathrm{Ar} \mathrm{min}^{-1}, 0.70 \mathrm{~L} \mathrm{Ar} \mathrm{min}{ }^{-1}, 0.72 \mathrm{~L} \mathrm{Ar}$ $\min ^{-1}$ and $3.5 \mathrm{~mL} 7 \% \mathrm{H}_{2}$ in $\mathrm{He} \mathrm{min}^{-1}$, respectively. The instrument was calibrated externally using four mixed standards prepared by dilutions of a QC 26 multi-element solution (CPI

180 International, Amsterdam) in $0.1 \mathrm{M} \mathrm{HNO}_{3}$, and internally by the addition of $100 \mu \mathrm{g} \mathrm{L}^{-1}$ of In 181 and Ir to all samples and standards. Data were acquired over a dwell period of $10 \mathrm{ms,}$, with 18250 sweeps per reading and three replicates.

184 Aqueous concentrations derived from ICP-MS were converted to dry weight concentrations 185 (in $\mu \mathrm{g} \mathrm{g}^{-1}$ ) from the volume of diluted digest and mass of macroalga dissolved in acid. Limits 186 of detection on this basis were $<2.5 \mu \mathrm{g} \mathrm{g}^{-1}$ for all trace elements analysed, and measured 187 concentrations in the reference macroalga were within $15 \%$ of published values with the 188 exception of $\mathrm{Br}$ and $\mathrm{Fe}$ (recoveries of about $50 \%$ and $70 \%$, respectively).

\subsection{Statistical analysis}

191 Correlation analysis was performed on paired data series using the Data Analysis Toolpak in 192 Excel 2016, with the strength of association reported as Pearson's moment correlation 
coefficient $(r)$ and the significance of the relationship as the probability of $r$ not being different from zero ( $p$, and where $\alpha=0.05$ ). One-way ANOVA and Tukey's post-hoc test were used in Minitab 17 to identify significant differences $(\alpha=0.05)$ in mean elemental concentrations and water contnets among macroalgae and parts thereof, and in mean elemental concentrations arising from the three analytical methods.

\section{Results and Discussion}

\subsection{Macroalgal water content and thickness}

201 Quantification of the water content of the macroalgal sections is critical for converting elemental concentrations from a fresh weight basis to a dry weight basis and for evaluating the impact of the fluid on x-ray behaviour and intensity (mainly through photoelectric absorption, but also via Compton scattering and internal reflections; Parsons et al., 2013). Mean percentage water, calculated from the fresh and dry weights of each section and shown in Table 1, ranged from about $50 \%$ to nearly $90 \%$, and for all species the order of descending water content was: apex > mid-frond > lower stipe. There was no statistical difference in water content between common sections of $F$. vesiculosus and $F$. serratus, but the water content of sections of $F$. ceranoides were significantly greater than corresponding sections of the former two species. The method of tissue cleaning made a difference to mean water content that was significant only for the lower-stipe of $F$. vesiculosus from Firestone Bay.

212 Thus, here, cleaning in MQW resulted in a higher percentage compared with sections having 213 undergone additional cleaning with ethanol

215 Fucoid section thickness, measured for XRF data correction, did not display a clear 216 dependency on species, location with respect to the frond or means of tissue cleaning. On

217 average, however, sections were thicker while wet $(1.02 \pm 0.15 \mathrm{~mm})$ than when freeze-dried $218(0.85 \pm 0.19 \mathrm{~mm})$. 
220 Table 1: Percentage water content of the fucoid macroalgal sections undergoing cleaning in

221 Milli-Q water (MQW) and ethanol, and/or MQW only. The mean and standard deviation of $222 n$ measurements is given in each case.

\begin{tabular}{lccccccc}
\hline & \multicolumn{2}{c}{ F. serratus $(n=5)$} & & \multicolumn{2}{c}{ F. vesiculosus $(n=5)$} & & F. ceranoides $(n=10)$ \\
\cline { 2 - 3 } apex & MQW & MQW+ethanol & & MQW & MQW+ethanol nn & & MQW \\
mid-frond & $81.2 \pm 1.8$ & $76.3 \pm 2.4$ & & $77.7 \pm 2.2$ & $73.1 \pm 1.7$ & & $86.7 \pm 1.9$ \\
lower stipe & $67.7 \pm 4.0$ & $63.7 \pm 5.1$ & & $62.6 \pm 3.7$ & $60.3 \pm 2.8$ & & $76.9 \pm 4.8$ \\
& $61.1 \pm 1.7$ & $54.2 \pm 5.3$ & & $61.8 \pm 1.3$ & $51.8 \pm 2.1$ & & $70.5 \pm 3.6$ \\
\hline
\end{tabular}

\section{3.2. XRF detection limits for trace elements in macroalgae}

225 XRF detection limits for trace elements in the fucoids, defined as three counting errors for a 226 200-second counting time, are presented in Table 2. Here, limits for all species, sectional

227 locations and cleaning methods have been pooled and are shown for samples analysed in 228 both the fresh state and after freeze-drying; with regard to the former, limits are shown on a 229 fresh weight basis and, after correction for water content, a dry weight basis. Note that for 230 some elements $(\mathrm{Cd}, \mathrm{Cr}, \mathrm{Cu}, \mathrm{Hg}, \mathrm{Ni}, \mathrm{Pb})$ limits have been averaged from at least fifteen 231 measurements in which the element was not detected by the instrument but a value of $3 \sigma$ 232 was returned directly; where less than fifteen sample sections were undetectable (As, $\mathrm{Br}, \mathrm{Fe}$, $233 \mathrm{Zn}$ ), limits were based on the values of $2 \sigma$ returned on detection and after multiplication by 2341.5.

236 Mean detection limits are generally lower when samples are analysed fresh than when 237 freeze-dried, presumably because the greater flexibility of wet macroalgal sections allows 238 them to be placed closer to the detector window of the instrument. However, when wet 239 weight concentrations are converted to a dry weight basis, detection limits are higher than 240 samples analysed dry. Here, we surmise that the effects of water on elemental dilution and x- 
ray absorption and scattering outweigh the benefits of increased proximity to the detector.

242 Overall, mean detection limits are lowest and average less than $10 \mu \mathrm{g} \mathrm{g}^{-1}$ (on both a dry

243 weight and wet weight basis) for $\mathrm{As}$ and $\mathrm{Pb}$ and are less than $25 \mu \mathrm{g} \mathrm{g}^{-1}$ for $\mathrm{Br}, \mathrm{Cu}, \mathrm{Hg}, \mathrm{Ni}$

244 and $\mathrm{Zn}$, and are similar to corresponding limits reported for dried sections of $F$. serratus

245 reported by Bull et al. (2017). Within these constraints, As and Fe were detected in all fucoid

246 section analyses performed in the present study $(n=180)$, while $\mathrm{Br}$ and $\mathrm{Zn}$ were detected in

247178 and 172 cases, respectively, with non-detection always associated with the analysis of

248 fresh samples. Note that although $\mathrm{Cu}$ and $\mathrm{Pb}$ were detected in some samples of $F$.

249 ceranoides, the number of cases ( $n=7$ and $n=5$, respectively) was too few for establishing

250 relationships between the different analytical approaches and differences among the three

251 sectional components of the macroalga.

253 Table 2: A summary (as mean \pm one standard deviation; $n>15$ ) of the Niton XRF detection 254 limits for trace elements in fucoid macroalgae analysed fresh and dry and for a 200-second 255 counting time $(\mathrm{dw}=$ dry weight $\mathrm{fw}=$ fresh weight $)$.

\begin{tabular}{|c|c|c|c|c|c|c|c|c|c|c|}
\hline & As & $\mathrm{Br}$ & $\mathrm{Cd}$ & $\mathrm{Cr}$ & $\mathrm{Cu}$ & $\mathrm{Fe}$ & $\mathrm{Hg}$ & $\mathrm{Ni}$ & $\mathrm{Pb}$ & $\mathrm{Zn}$ \\
\hline dry, $\mu g g^{-1} d w$ & $4.7 \pm 1.0$ & $17.9+4.6$ & $26.3 \pm 2.3$ & $6.1 \pm 2.2$ & $16.2+4.2$ & $24.5 \pm 6.7$ & $12.3 \pm 2.8$ & $14.4+3.8$ & $5.9 \pm 1.0$ & $11.7 \pm 2.7$ \\
\hline fresh, $\mu \mathrm{gg}^{-1} \mathrm{fw}$ & $1.6 \pm 0.2$ & $4.7 \pm 1.2$ & $14.4 \pm 2.4$ & $7.9 \pm 2.0$ & $5.3 \pm 1.0$ & $6.8 \pm 1.3$ & $5.0 \pm 1.2$ & $5.0 \pm 1.0$ & $2.3 \pm 0.5$ & $3.5 \pm 1.1$ \\
\hline fresh, $\mu g g^{-1} d w$ & $6.6 \pm 2.0$ & $20.1+9.5$ & $61.0 \pm 23.4$ & $32.3 \pm 11.9$ & $22.2+8.5$ & $28.2 \pm 10.1$ & $21.2 \pm 9.0$ & $21.0+8.9$ & $9.7 \pm 3.8$ & $14.3+5.5$ \\
\hline
\end{tabular}

\subsection{Comparison of elemental concentrations when analysed wet and dry}

259 Figure 2 compares the dry weight concentrations of readily detectable elements (As, $\mathrm{Br}, \mathrm{Fe}$,

$260 \mathrm{Zn}$ ) in the fucoids that were returned by the Niton XRF when analysed dry, [XRF-dry], and

261 when analysed fresh and individually corrected for water content, [XRF-fresh]. Note that

262 here, data for each element are not discriminated by species, location on the frond or means

263 of tissue cleaning. Also shown are the best-fit equations (forced through the origin) that

264 define each element, along with corresponding Pearson's moment correlation coefficients 
and the line signifying unit slope. In all cases, and despite changes in thickness and

266 morphology incurred by freeze-drying, elemental concentrations arising from both

267 approaches were highly correlated $(p<0.01)$ with gradients exceeding unit value; that is,

268 concentrations returned when analysed dry were, on average, higher than concentrations

269 returned when analysed fresh but dry-weight corrected. This suggests that the presence of

270 internal and surficial water suppresses the strength of fluorescent x-rays reaching the

271 detector window of the FP-XRF through absorption and scattering. Consistent with this

272 assertion, deviation from unit slope is greatest for Fe, whose characteristic x-rays are of low

273 energy $\left(\mathrm{K}_{\alpha}=6.405 \mathrm{keV} ; \mathrm{L}_{\alpha}=0.705 \mathrm{keV}\right)$ and relatively easily absorbed by water, and least

274 for $\mathrm{Br}$, whose characteristic $\mathrm{x}$-rays are of higher energy $\left(\mathrm{K}_{\alpha}=11.924 \mathrm{keV} ; \mathrm{L}_{\alpha}=1.481 \mathrm{keV}\right)$

275 and, therefore, less easily absorbed.

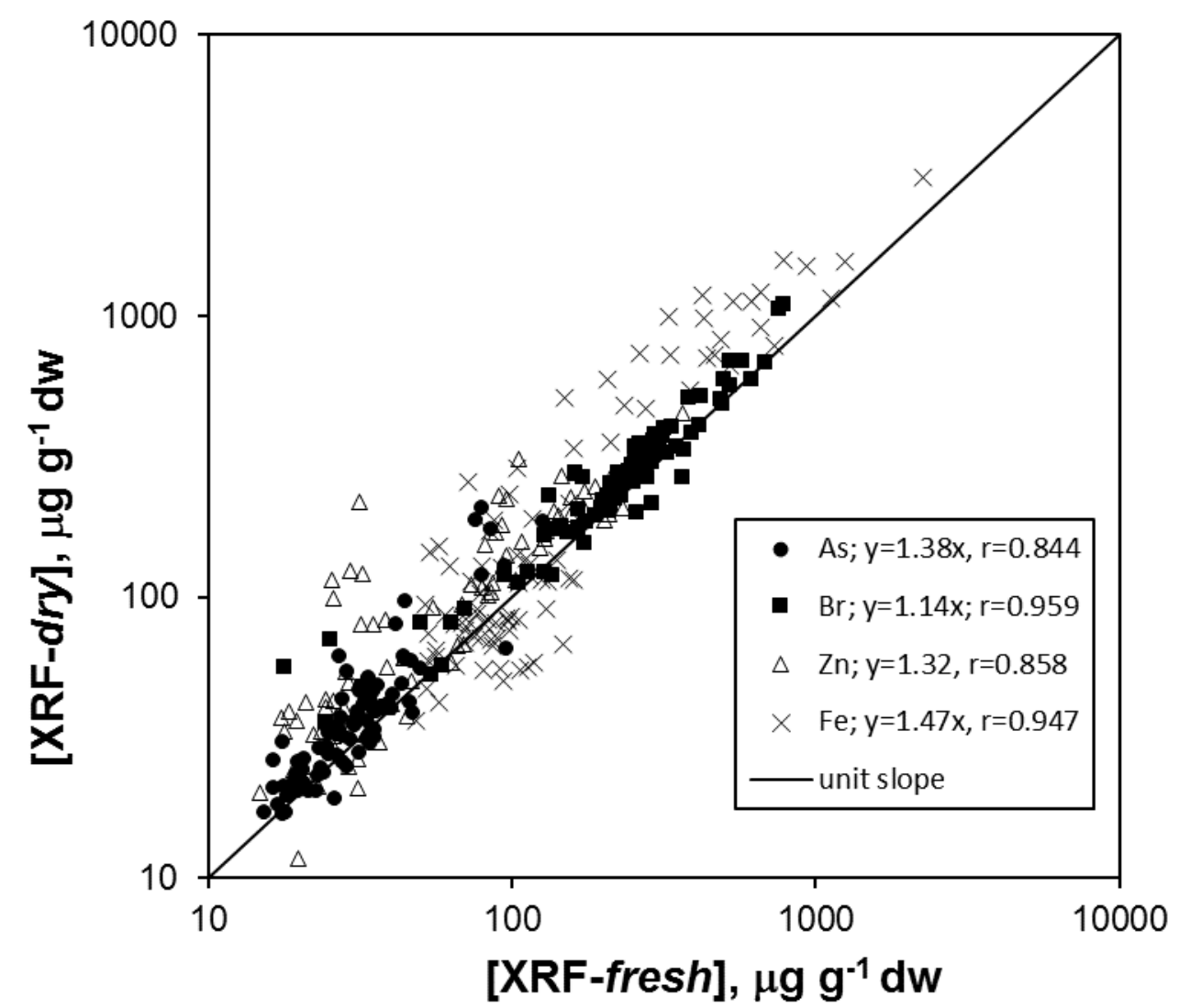

277 Figure 2: Dry weight elemental concentrations in the coastal and brackish water fucoid

278 macroalgae returned by the Niton XRF when analysed dry and fresh. Shown inset for each

279 element are equations of best fit when forced through the origin. 
281 3.4. Inter-and intra-species variations in elemental concentrations and comparison with

$282 \quad I C P-M S$

283 Figures 3 to 6 show the dry-weight concentrations of $\mathrm{As}, \mathrm{Br}, \mathrm{Fe}$ and $\mathrm{Zn}$ in the different parts

284 of each species of fucoid and as determined by the two XRF approaches (that is, analysis of

285 fresh sections versus analysis of freeze-dried sections) and by ICP-MS following acid

286 digestion. Note that all data presented are for tissues cleaned in MQW only and that results

287 arising from samples subjected to additional cleaning with ethanol were very similar.

288 Regarding As, mean concentrations were not statistically different among the different

289 methods of determination with the exception of the lower stipe in F. serratus, where

290 concentrations were lower when analysed by XRF in the fresh state than by ICP, and the

291 apex in F. ceranoides, where concentrations were higher when analysed dry by XRF.

292 Among the different parts of the frond, mean concentrations were generally higher in the

293 apex than the mid-frond and lower stipe, an effect that was evident from each analytical

294 approach in at least one species of fucoid. Overall, absolute concentrations of As were

295 greatest in the apex of $F$. ceranoides, and concentrations were significantly greater in the

296 mid-frond and lower stipe of $F$. ceranoides than in corresponding parts of both $F$. serratus

297 and F. vesiculosus according to at least one analytical approach.

299 With respect to $\mathrm{Br}$, results arising from ICP-MS analysis have been neglected due to loss of

300 volatile forms (e.g. $\mathrm{HBr}$ and $\mathrm{Br}_{2}$ ) during acid-oxidizing digestion, an effect that is often

301 significant when opening the digestion vessel at the end of the mineralisation process (Di

302 Narda et al., 2001). Mean concentrations of the halogen were never statistically different

303 between the two XRF approaches and concentrations were not different among the three

304 sectional components of $F$. serratus. Concentrations were, however, significantly lower in 
the stipe of $F$. vesiculosus than in its apex, and significantly higher in the stipe of $F$.

306 ceranoides than in the apex where the lowest overall mean concentrations were observed.

308 Among the elements readily detected, concentrations of Fe were most variable among

309 replicates. Consequently, there were no statistical differences observed between the two

310 XRF approaches, despite mean concentrations returned being double when analysed dry in

311 some cases. Determination by ICP-MS returned significantly lower concentrations than one

312 or both XRF approaches (and by factors up to an order of magnitude) for the mid-fronds of

313 both $F$. serratus and $F$. ceranoides and the apex and lower stipe of the latter.

315 Statistical differences in the mean concentrations of $\mathrm{Zn}$ were observed among the three

316 analytical approaches only for the lower stipe of $F$. vesiculosus (lower by XRF after section

317 drying), and the apex of $F$. serratus and apex and mid-frond of $F$. ceranoides (higher when

318 analysed by XRF after drying than by both other approaches). With the exception of the apex

319 analysed by XRF when fresh, mean concentrations of Zn were always statistically higher in

320 F. ceranoides than corresponding concentrations in F. vesiculosus. In fewer cases, mean

321 concentrations were higher in $F$. ceranoides than in $F$. serratus and in $F$. serratus than in $F$. 322 vesiculosus. 
331 Figure 3: Dry weight concentrations of As in the different parts of the fucoid species and as

332 returned by FP-XRF analysis of fresh sections (grey bars) and dry sections (open bars) and

333 by ICP-MS analysis following acid digestion (hatched bars). Errors represent the standard

334 deviation about the mean of $n$ measurements.

335
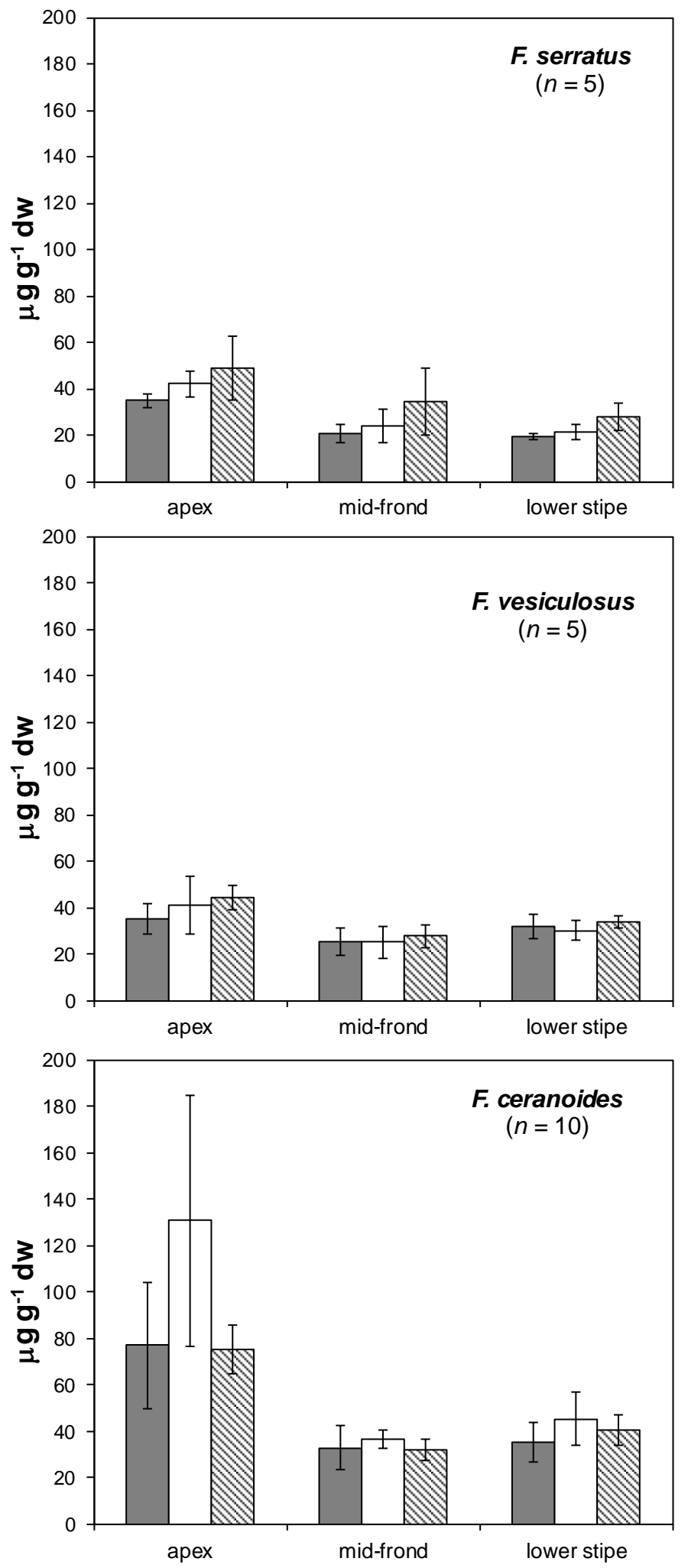

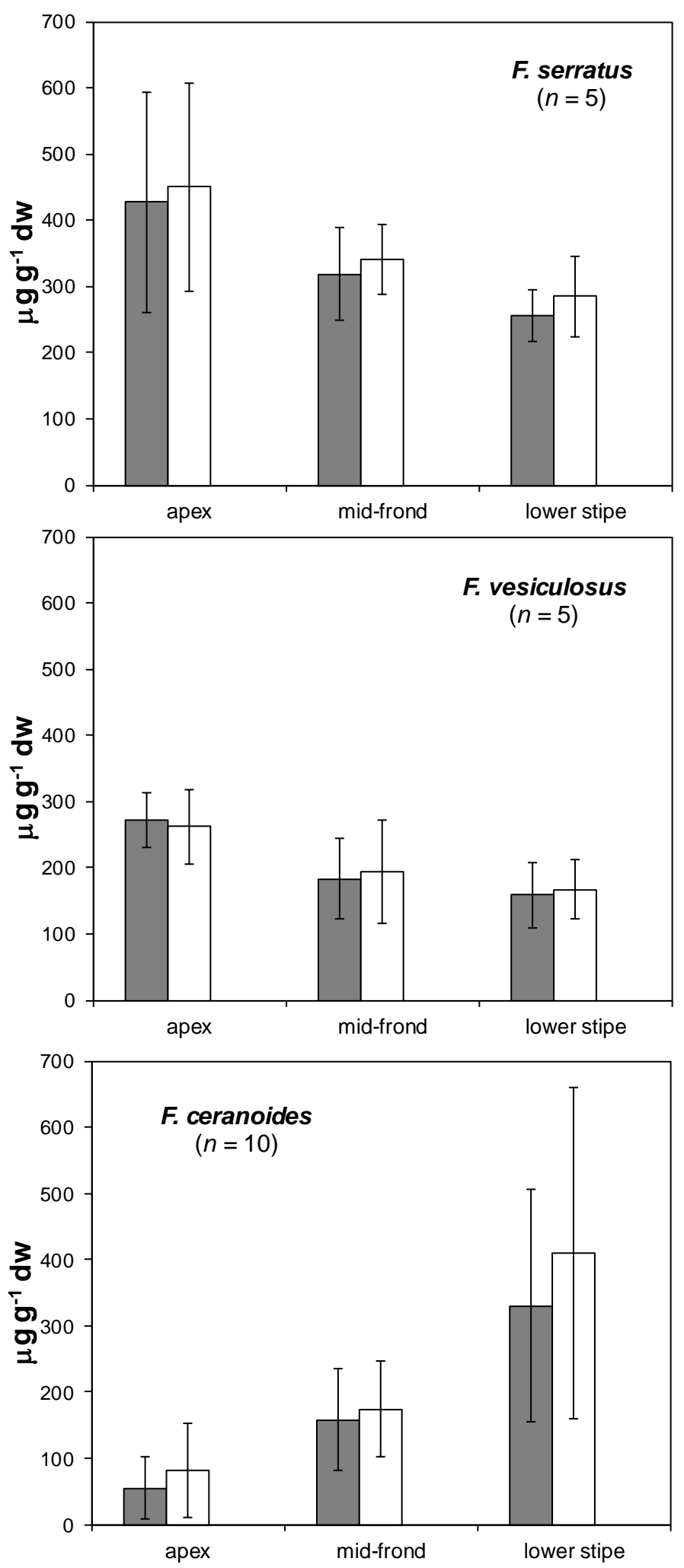

337 Figure 4: Dry weight concentrations of $\mathrm{Br}$ in the different parts of the fucoid species and as 338 returned by FP-XRF analysis of fresh sections (grey bars) and dry sections (open bars).

339 Errors represent the standard deviation about the mean of $n$ measurements. 
340 Figure 5: Dry weight concentrations of Fe in the different parts of the fucoid species and as

341 returned by FP-XRF analysis of fresh sections (grey bars) and dry sections (open bars) and

342 by ICP-MS analysis following acid digestion (hatched bars). Errors represent the standard

343 deviation about the mean of $n$ measurements.
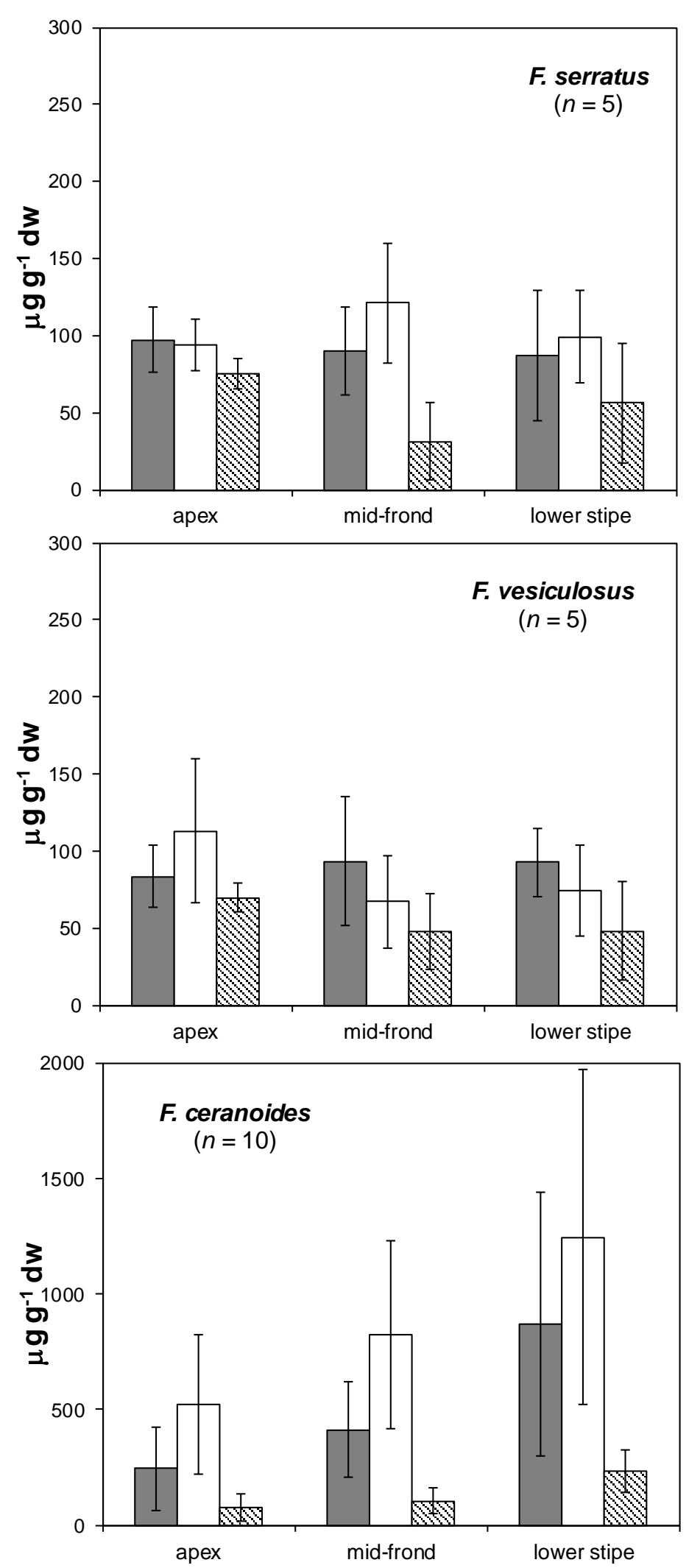
366 Figure 6: Dry weight concentrations of $\mathrm{Zn}$ in the different parts of the fucoid species and as

367 returned by FP-XRF analysis of fresh sections (grey bars) and dry sections (open bars) and

368 by ICP-MS analysis following acid digestion (hatched bars). Errors represent the standard

369 deviation about the mean of $n$ measurements.
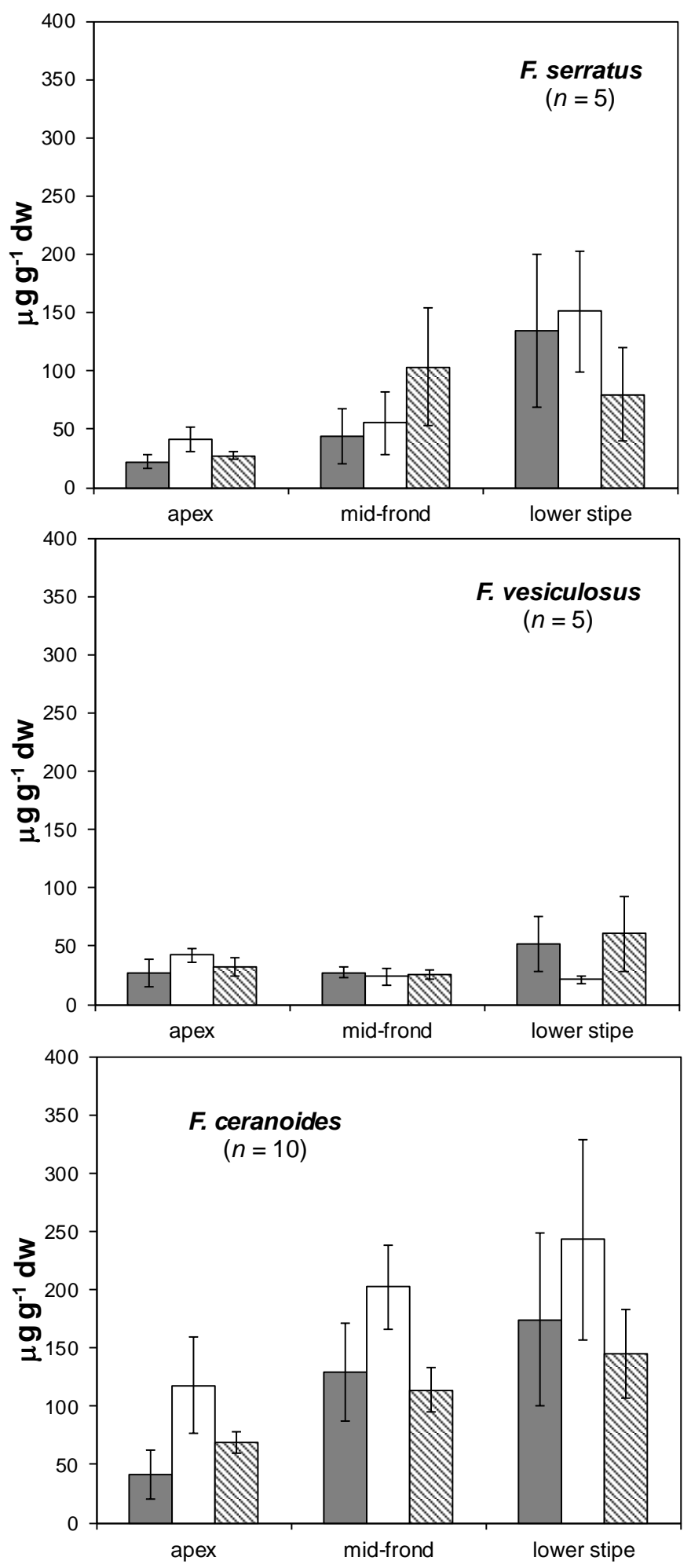
372 In a previous article, we demonstrated the potential of FP-XRF for determining trace element

373 concentrations in different species of dried coastal macroalgae in a laboratory accessory

374 stand (Bull et al., 2017). The technique has distinct advantages over conventional methods

375 involving sample digestion that include reduced time and costs, non-destruction of material

376 (of particular significance to archived specimen banks), increased sample throughput,

377 minimal operator training, capability of exploring tissue spatial variability and avoidance of

378 hazardous wastes. Because monitoring in situ requires direct analysis without drying,

379 however, the present study evaluated the effects of the presence of internal and surficial

380 water on elemental concentrations returned for various fucoids. Thus, a comparison of

381 results arising from the analysis of fresh sections that had been dry-weight normalised and

382 the analysis of sections that had been subsequently freeze-dried revealed a greater sensitivity

383 of the latter approach but results that were highly correlated for all elements considered.

384 Lower dry-weight concentrations returned when analysed fresh are attributed to the

385 absorption of characteristic x-rays by water contained within or at the surface of the 386 macroalga.

388 Since variations in the percentage water in a given section of fucoid were small, with 389 relative standard deviations of less than $5 \%$ in most cases, instantaneous, quantitative 390 correction for macroalgal water content may be readily accomplished through species- and 391 section-specific algorithms; alternatively, it is possible that the fluorescence of $\mathrm{Cl}\left(\mathrm{K}_{\alpha}=2.62\right.$

$392 \mathrm{keV}, \mathrm{K}_{\beta}=2.82 \mathrm{keV}$ ) could be used as a direct proxy for water content if local salinity is

393 known (Tjallingii et al., 2007). Additional, element-specific corrections for x-ray absorption 394 by water based on the gradients of the relationships between samples analysed fresh and dry 395 (Figure 2) would also be required for complete quantification of concentrations on a dry 396 weight basis. In practice, corrections for the effects of water may be stored in the Niton XRF 
software as alternative calibrations in the low density mode by adding appropriate slopes and, if necessary, intercepts.

400 In most cases, dry-weight concentrations of As and Zn obtained by the analysis of fresh and

401 dried sections of fucoids by FP-XRF were not statistically different to corresponding

402 concentations derived independently by ICP-MS following acid digestion. For Fe in the

403 estuarine macroalga, F. ceranoides, however, we attribute significantly lower results arising

404 from ICP analysis to the incomplete release of Fe from the macroalga and to the presence of

405 silt particles on the tissue surface that evaded cleaning and that were detected by the XRF

406 but not completely digested by $\mathrm{HNO}_{3}$. Among the elements analysed, the latter effect would

407 be most significant for Fe given its high concentration in fine sediment from the Tavy

408 Estuary (about 60,000 $\mu \mathrm{g} \mathrm{g}^{-1}$ determined on dried, intertidal silt by FP-XRF in a higher

409 density, 'mining' mode, and compared with As and Zn concentrations of 90 and $250 \mu \mathrm{g} \mathrm{g}^{-1}$,

410 respectively). The heterogeneous dispersion of silt on the tissue surface would also account

411 for the relatively high variability of Fe concentrations measured by XRF among replicates of

412 the same sample section.

\section{3.4. Deployment of the XRF in situ}

415 With the effects of macroalgal water evaluated and quantified, the feasibility of employing

416 the Niton FP-XRF spectrometer in situ was tested. Thus, the Tavy Estuary was revisited and

417 sections from $F$. ceranoides and $F$. vesiculosus analysed under the operating conditions

418 described above (instrument mode, counting time, energy ranges) after cleaning in MQW,

419 dissection, blotting dry and thickness measurement with callipers. Initial attempts using the

420 XRF handheld against sections placed on a solid but smooth surface (e.g. a plastic tray on a

421 flat rock) and activated manually via the tilting touchscreen proved unsuccessful for a

422 number of reasons. For example, positioning the XRF window such that it covered the 
423 macroalgal section completely was difficult, despite the aid of live video-footage generated

424 by a colour charge-coupled device camera and sampling imaging system adjacent to the

425 detector; moreover, once positioning had been accomplished, holding the instrument still for

426 a suitable length of time against the slimy, fucoid surface was not possible. A moving x-ray

427 source over a low density, irregular sample also poses a safety hazard to the operator though

428 radiation scattering; although this hazard could be minimised by using a backscatter collar-

429 shield around the nose of the instrument (Figure 7a), the additional size and weight of

430 equipment further inhibited accurate and steady positioning of the detector window.

432 Successful application of the XRF in the field was, however, accomplished when coupled to

433 a lightweight $(\sim 2.5 \mathrm{~kg})$ and small-volume $\left(300 \mathrm{~cm}^{3}\right)$ mobile test-stand (ThermoScientific,

434 PN 430-032) and laptop (Figure 7b). Here, the test-stand was placed on a level, stable

435 surface and the instrument subsequently securely fixed to the steel baseplate with the nose

436 pointing upwards. Individual sample sections were placed on polyester film and positioned

437 centrally over the detector window with the aid of plastic tweezers and, if necessary, held

438 flat and in place with weights (e.g. small stones) at each end (Figure 7c). Once the shielded

439 (tungsten-plastic) stand lid was closed, measurements were activated remotely using the

$440 \quad$ laptop and via USB.

442 Essentially, this is the same approach as that employed in the laboratory using the accessory-

443 stand. Additional benefits of performing measurements in situ, however, include the

444 development of a strategy or focus that is iterative or directly informed by immediate results,

445 identification of contamination hot-spots, elements of concern or the effects of a pollution

446 incident, determination of which samples to return to the laboratory for further

447 characterisation, and little or no degradation of macroalgae should transport to the laboratory

448 be otherwise time-consuming. With three people in the field and working concurrently on 
separate tasks (sampling, sample processing and analysis), algal section throughput for a 200

450 second counting time was about 15 per hour, and with a single, fully-charged battery, the

451 XRF could be deployed for a period of up to six hours. Given the weight of equipment

452 involved (about $15 \mathrm{~kg}$ for the XRF, stand, laptop and cases), set up and measurement are

453 also possible with a single operator, although throughput would be significantly reduced

454 because of the requirement for an individual to conduct multiple tasks successively or

455 concurrently.

457 For different sections analysed in situ, concentrations measured directly were converted to

458 dry weight concentrations using the average (generic) percentage water for a given type of

459 section of a particular species and subsequently corrected for x-ray water absorption by

460 applying the element-specific gradients defining the relationship between samples analysed

461 fresh and dry (Figure 2). In Figure 8, results for As and Zn derived accordingly, [XRF-in

462 situ], are shown for samples in which concentrations were subsequently determined by ICP-

463 MS following drying and acid digestion. For both elements, correlations were significant ( $p$

$464<0.05)$ with $r$ values exceeding the US EPA quantitative screening criterion of 0.7

465 (Environmental Protection Agency, 2007). For Fe, concentrations derived in situ were

466 significantly correlated with but considerably higher than those derived independently by

467 ICP-MS for reasons outlined above. With respect to F. vesiculosus in the Tavy, mean

468 concentrations of As and $\mathrm{Zn}$ derived in situ (67 and $200 \mu \mathrm{g} \mathrm{g}^{-1}$ ) are also similar to mean

469 values reported in the literature for the upper estuary ( 86 and $382 \mu \mathrm{g} \mathrm{g}^{-1}$ respectively;

$470 \quad$ Rainbow et al., 2011). 

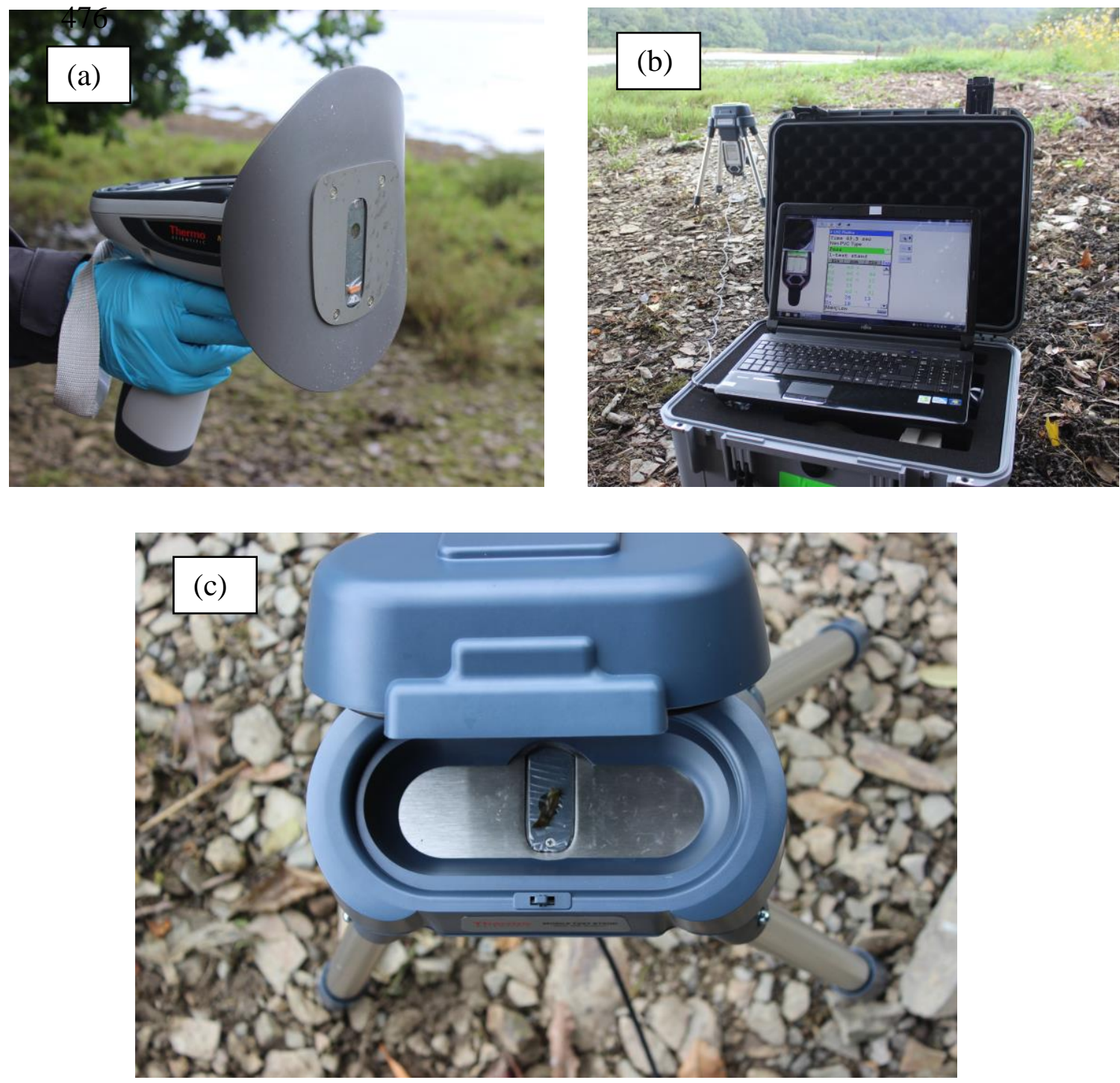

492 Figure 7: (a) The Niton XL3t plus backscatter shield; (b) configuration of the instrument in

493 situ and coupled to the portable stand and laptop; (c) a fucoid section placed above the

494 detector window and within the stand.

495

496

497

498 
Figure 8: Relationship between As and $\mathrm{Zn}$ concentrations in $F$. ceranoides and $F$.

500 vesiculosus determined by ICP-MS following acid digestion and by FP-XRF deployed in

501 situ and after correction for the content and x-ray absorption of water.

502

503

504

505

506

507

508

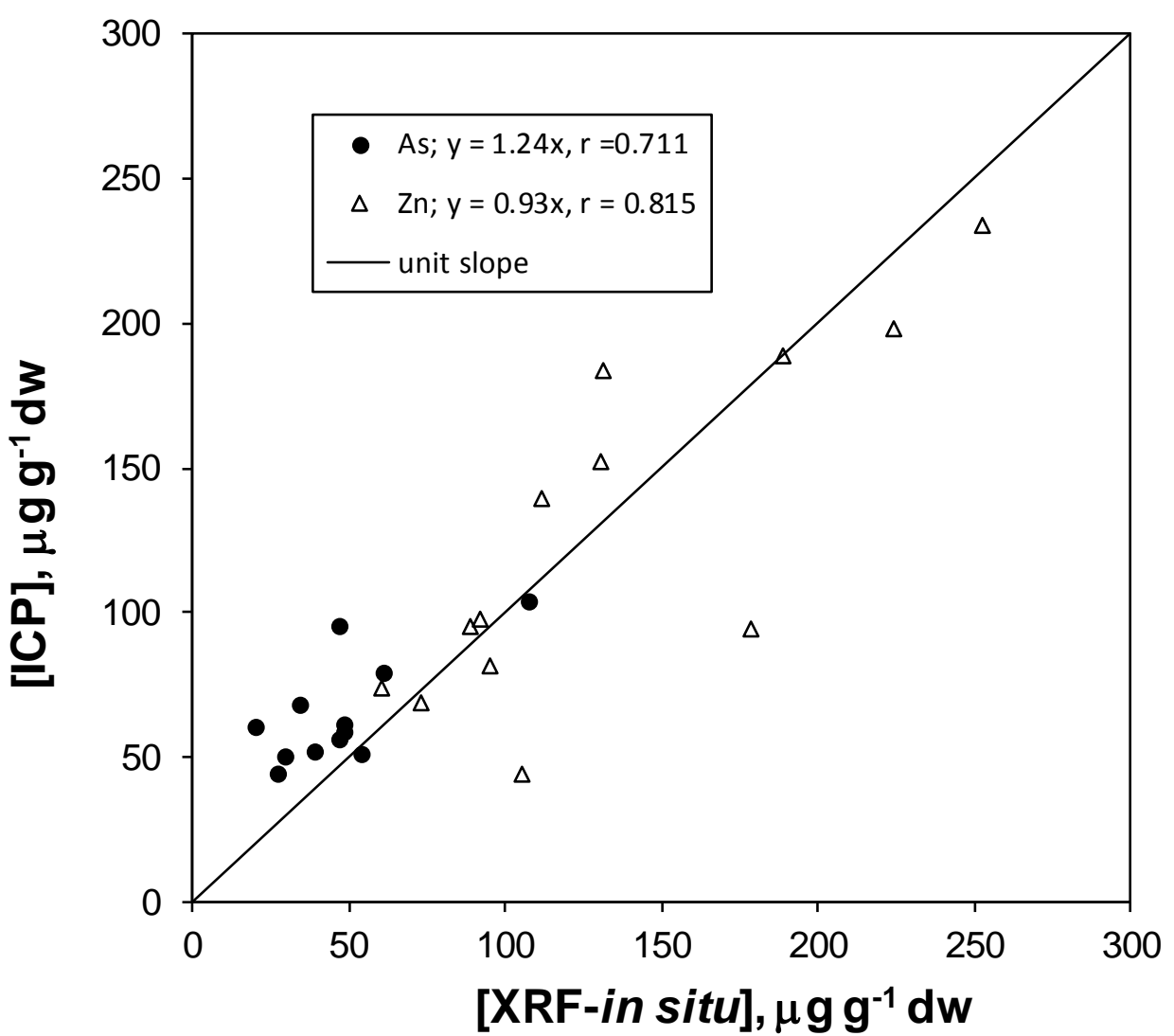

\section{4. Conclusions}

516 Although FP-XRF does not have the capability of sub-part per million analyses to replace

517 atomic or mass spectrometry, this study has shown that the Niton XL3t provides a rapid,

518 cost-effective and non-destructive means of measuring various trace elements in both fresh

519 and dry fucoid species of macroalgae, provided that a low density mode with thickness

520 correction is employed. The analytical conditions described (mode of application,

521 collimation, counting time, energy ranges) allow the ready quantification of As to dry weight

522 concentrations down to a few $\mu \mathrm{g} \mathrm{g}^{-1}$ and $\mathrm{Br}, \mathrm{Fe}$ and $\mathrm{Zn}$ to concentrations of a few tens of $\mu \mathrm{g}$

$523 \mathrm{~g}^{-1}$; measurement of $\mathrm{Cu}$ and $\mathrm{Pb}$ in fucoids is also possible in moderately to highly

524 contaminated sites. Coupled to a mobile test-stand and laptop, the instrument can be 
deployed in situ for rapid diagnostic and strategic purposes and to evaluate intra- and inter-

526 specific concentration variations, with full quantification possible after empirical adjustment

527 of data for the effects of water on sample weight and x-ray absorption.

\section{Acknowledgements}

530 We are grateful to Dr Andrew Fisher for technical support during the ICP-MS analysis. This 531 study was funded partly by a UoP HEIF V Marine Institute grant.

\section{References}

534 Brito, G.B., de Souza, T.L., Bressy, F.C., Moura, C.W.N., Korn, M.G.A., 2012. Levels and 535 spatial distribution of trace elements in macroalgae species from the Todos os Santos Bay, 536 Bahia, Brazil. Marine Pollution Bulletin 64, 2238-2244.

538 Boubonari, T., Malea, P., Kevrekidis, T., 2008. The green seaweed Ulva rigida as a

539 bioindicator of metals $(\mathrm{Zn}, \mathrm{Cu}, \mathrm{Pb}$ and $\mathrm{Cd})$ in a low-salinity coastal environment.

540 Botanica Marina 51, 472-484.

542 Bruhn, A., Dahl, J., Nielsen, H.B., Nikolaisen, L., Rasmussen, M.B., Markager, S., Olesen,

543 B., Arias, C., Jensen, P.D., 2011. Bioenergy potential of Ulva lactuca: Biomass yield,

544 methane production and combustion. Bioresource Technology 102, 2595-2604.

546 Bull, A., Brown, M.T., Turner, A., 2017. Novel use of field-portable-XRF for the direct

547 analysis of trace elements in marine macroalgae. Environmental Pollution 220, 228-233. 548 
549 Cairrão, E., Pereira, M.J., Pastorinho, M.R., Morgado, F., Soares, A.M.V.M., Guilhermino,

550 L., 2007. Fucus spp. as a mercury contamination bioindicator in costal areas (Northwestern

551 Portugal). Bulletin of Environmental Contamination and Toxicology 79, 388-395.

553 Chan, S.M., Wang, W.X., Ni, I.H., 2003. The uptake of Cd, Cr, and Zn by the macroalga

554 Enteromorpha crinita and subsequent transfer to the marine herbivorous rabbitfish, Siganus

555 canaliculatus. Archives for Environmental Contamination and Toxicology 44, 298-306.

557 Di Narda, F., Toniolo, R., Bontempelli, G., 2001. Improved microwave digestion procedure

558 for inductively coupled plasma mass spectrometric determinations of inorganic bromide

559 residues in foodstuffs fumigated with methyl bromide. Analytica Chimica Acta 436, 245-

560252

561

562 Duarte, C.M., Losada, I.J., Hendricks, I.E., Mazarrasa, I., Marba, N., 2013. The role of 563 coastal plant communities for climate change mitigation and adaptation. Nature Climate

564 Change 3, 961-968.

566 Environmental Protection Agency, 2007. Method 6200 - Field portable x-ray fluorescence

567 spectrometry for the determination of elemental concentrations in soil and sediment.

568 http://www3.epa.gov/epawaste/hazard/testmethods/sw846/pdfs/6200.pdf. Accessed 7/16.

570 Guinda, X., Juanes, J.A., Puente, A., Revilla, J.A., 2008. Comparison of two methods for

571 quality assessment of macroalgae assemblages, under different pollution types. Ecological

572 Indicators 8, 743-753. 
574 Martin, M.H., Nickless, G., Stenner, R.D., 1997. Concentrations of cadmium, copper, lead,

575 nickel and zinc in the alga Fucus serratus in the Severn estuary from 1971 to 1995.

576 Chemosphere 43, 25-334.

577

578 Matias, M.G., Arenas, F., Rubal, M., Pinto, I.S., 2015. Macroalgal composition determines

579 the structure of benthic assemblages colonizing fragmented habitats. PLOS ONE 10, article

580 e0142289, DOI: 10.1371/journal.pone.0142289.

581

582 Mulholland, R., Turner, A., 2011. Accumulation of platinum group elements by the marine 583 gastropod Littorina littorea. Environmental Pollution 159, 977-982.

585 Parsons, C., Grabulosa, E.M., Pili, E., Floor, G.H., Roman-Ross, G., Charlet, L., 2013.

586 Quantification of trace arsenic in soils by field-portable x-ray fluorescence spectrometry:

587 Considerations for sample preparation and measurement conditions. Journal of Hazardous

588 Materials 262, 1213-1222.

590 Rainbow, P.S., 2006. Biomonitoring of trace metals in estuarine and marine environments.

591 Australasian Journal of Ecotoxicology 12, 107-122.

593 Rainbow, P.S., Kriefman, S., Smith, B.D., Luoma, S.N., 2011. Have the bioavailabilities of 594 trace metals to a suite of biomonitors changed over three decades in SW England estuaries 595 historically affected by mining? Science of the Total Environment 409, 1589-1602.

597 Reis, P.A., Cassiano, J., Veiga, P., Rubal, M., Sousa-Pinto, I., 2014. Fucus spiralis as

598 monitoring tool of metal contamination in the northwest coast of Portugal under the 
European Water Framework Directives. Environmental Monitoring and Assessment 186,

$600 \quad 5447-5460$.

601

602 Rüdel, H., Fliedner, A., Kosters, J., Schroter-Kermani, C ., 2010. Twenty years of elemental 603 analysis of marine biota within the German Environmental Specimen Bank-a thorough look

604 at the data. Environmental Science and Pollution Research 17, 1025-1034.

605

606 Sondergaard, J., Bach, L., Gustavson, K., 2014. Measuring bioavailable metals using

607 diffusive gradients in thin films (DGT) and transplanted seaweed (Fucus vesiculosus), blue

608 mussels (Mytilus edulis) and sea snails (Littorina saxatilis) suspended from monitoring

609 buoys near a former lead-zinc mine in West Greenland. Marine Pollution Bulletin 78, 102-

610109.

611

612 Tabarsa, M., Rezaei, M., Ramezanpour, Z., Waaland, J.R., 2012. Chemical compositions of 613 the marine algae Gracilaria salicornia (Rhodophyta) and Ulva lactuca (Chlorophyta) as a 614 potential food source. Journal of the Science of Food and Agriculture 92, 2500-2506.

615

616 Tjallingii, R., Röhl, U., Kölling, M., Bickert, T., 2007. Influence of the water content on x617 ray fluorescence core-scanning measurements in soft marine sediments. Geochemistry,

618 Geophysics, Geosystems 8, Q02004, doi:10.1029/2006GC001393.

619

620 Turner, A., Solman, K.R., 2016. Analysis of the elemental composition of marine litter 621 by field-portable-XRF. Talanta 159, 262-271. 
623 Viana, I.G., Aboal, J.R., Fernàndez, J.A., Real, C., Villares, R., Carballeira, A., 2010. Use of

624 macroalgae stored in an Environmental Specimen Bank for application of some European

625 Framework Directives. Water Research 44, 1713-1724.

626

627 Zbikowski, R., Szefer, P., Latala, A., 2006. Distribution and relationships between selected

628 chemical elements in green alga Enteromorpha sp from the southern Baltic. Environmental

629 Pollution 143, 435-448. 